\title{
THE IMPACTS OF UNESCO'S BUILT HERITAGE CONSERVATION POLICY (2010-2020) ON HISTORIC JEDDAH BUILT ENVIRONMENT
}

\author{
MOHAMMED BAGADER \\ College of Architecture and Design, Effat University, Saudi Arabia
}

\begin{abstract}
In 2009, the Saudi Commission of Tourism and Antiquities (SCTA), currently the Saudi Commission of Tourism and National Heritage (SCTH), in collaboration with Jeddah Municipality, attempted to inscribe Historic Jeddah in the UNESCO World Heritage Sites (WHS) list to promote the idea of built heritage conservation and lead to tourism development. This attempt was turned down due to the ICOMOS committee suggestions. In 2010, as a response to this informal rejection, the SCTA and Jeddah Municipality worked in tandem to apply a built heritage conservation scheme that copes with UNESCO standards (known as the UNESCO Policy) in order to nominate Historic Jeddah (or some heritage areas/nominated property) again in light of the ICOMOS committee suggestions. This led to a radical shift in the manner of dealing with urban heritage sites in Saudi Arabia in terms of the general framework, the decision-making, the implementation and the management processes. This remarkable shift led to Historic Jeddah to becoming a world heritage site in July 2014. This paper attempts to understand the actual impacts of the UNESCO Policy (UNESCO standards) on the built environment of Historic Jeddah with regard to both the urban/spatial planning and architectural typology. In order to achieve this objective, the author will study several conservation efforts by different actors (stakeholders) from different categories (governmental, non-governmental organizations (NGOs), public and private sectors).

Keywords: built heritage, conservation, impacts, policy, UNESCO WHS list, Saudi Arabia, Historic Jeddah.
\end{abstract}

\section{INTRODUCTION}

"The pressures facing the historic urban environment are many. Globalization, development, demographic change, and economic pressures are the main factors that directly drive change in the urban environment and impact the preservation of historic urban environments" [1].

Historic urban cores are very important to any nation due to their historical, social and cultural values [2]. They also symbolize and reflect identities, traditions and norms of each society or community [3]. Therefore, they require special attention to survive and safeguard; however, Historic Jeddah is one such urban centre that has encountered severe deterioration, especially after the city wall was demolished in 1947, when most of the native families left their traditional homes and moved beyond the old city boundaries [4]. This has massive negative impacts on urban historical sites in Saudi in general and Historic Jeddah in particular, which led to demolition, destruction and caused many sites to vanish and disappear.

Harrison and Hitchcock [5] believe that any built heritage effort required a clear vision "policy", including a series of legal, technical and financial conservation processes. Therefore, Radoine [6] argues that, when dealing with conservation, one has to realize that heritage, which has endured for centuries can be neither grasped nor discerned all at once, within the limits of time and place. However, the Saudi built heritage conservation concept has been through a number of shifts in terms of the general frameworks, the ideological approaches and the purposes of these conservation efforts [7]. These shifts have had huge 
impacts (mostly negatives) in the built heritage sites socially, culturally, urbanely and architecturally. Historic Jeddah is one of the perfect examples of these shifts due to several conservation policies that have been implemented in the heritage area since 1970 and its historical values as an Islamic coastal city. Bagader [8] argues that Historic Jeddah has witnessed three main built heritage conservation policies that safeguarded the remaining heritage sites in the old city, namely Mathew's Policy (1970-2006), the SCTA Policy (20062010) and the UNESCO Policy (2010-2020). This paper focuses on the UNESCO built heritage conservation policy and its impacts on Historic Jeddah built environment.

\section{METHODOLOGY USED}

The methodology used in this paper is a mixed approach of gathering data through a secondary (literature review) and primary sources (data collection phases: empirical work) which includes: government and non-governmental archives including (documents and maps), official and non-official reports, and direct observation of selected sites, questionnaires, face-to-face semi-structured interviews, and design analysis. This research was adapted as a case study approach to achieve the paper objectives; therefore, fieldwork was necessary. The fieldwork was carried out in three phases: collecting selected data "documentation"; site visits "observations"; and conducting interviews with selected actors and stakeholders. Both quantitative and qualitative data were collected. The fieldwork that took place in Historic Jeddah during three periods: June 2013-November 2013; JanuaryFebruary 2014; and March-April 2015.

\section{THE ACTUAL IMPACTS OF THE UNESCO POLICY (2010-2020) ON THE BUILT ENVIRONMENT OF HISTORIC JEDDAH}

"During the last four years, Historic Jeddah was under construction. Many revitalization projects have been implemented, which have had a huge impact on the physical conditions of the heritage buildings. A variety of stakeholders have been involved and participated" [9].

As mentioned in the earlier, in 2008-2009 SCTA and Jeddah Municipality attempted to inscribe Historic Jeddah but this attempt was turn down due to many reasons, with precise comments from the ICOMOS members panel employ the UNESCO standards. Therefore, the UNESCO Policy was mainly based upon these ICOMOS rejection reasons and suggestions. These suggestions were essentially about the high level of deterioration of the physical condition of the historical area, and the lack of heritage management in the site, the lack of a clear financial plan and the lack of the touristic approach.

The policy has a "touristic" nature by focusing on inscribing Historic Jeddah at the UNESCO WHS list and promotes tourism development by making Historic Jeddah a local, national and international tourist destination. Section 2(b) of the SCTA report [10] stated that: "A new policy (UNESCO) was adapted in order to safeguard Historic Jeddah with taken the previous and recent visions into consideration for the next ten years (2010-2020)." Involving all stakeholders and actors from all categories, rehabilitating the surviving heritage sites (i.e. the nominated propriety), possessing financial funds, gaining governmental supports, regulating a protection law, coping with the UNESCO standards and finally resubmitting the nomination file again in the near future were the main objectives of this policy [11]. In addition to the objectives of the new policy, the ultimate goal was to safeguard Historic Jeddah and revive the area by adapting the "living heritage" concept [11]. This was the documented policy that the SCTA, in collaboration with Jeddah Municipality, has designed and regulated for the future for Historic Jeddah for the upcoming 20 years, starting from 2010. 


\subsection{The policy impacts on Historic Jeddah urban fabric}

The UNESCO Policy has been affecting the urban planning of Historic Jeddah at different levels, as shown in the following sections.

\subsubsection{The founding of Historic Jeddah Municipality}

First of all, before launching the UNESCO Policy in the historical area, Historic Jeddah was under Al-balad Municipality [12], which contained the historical districts and the surrounding districts such as Alkandra district. However, the UNESCO Policy suggested that Historic Jeddah has to have its own municipality with a clear duties and visions [12]. This means that Jeddah Municipality (i.e. headquarter) finally considers Historic Jeddah a local heritage site that requires extra attention to conserve it, which is the opposite of what happened in the past. This municipality is working closely with the SCTA office in Historic Jeddah in order to safeguard and upgrade the area. The Historic Jeddah Municipality report [12] mentioned that the new municipality has attempted to apply the current conservation policy approved by the Jeddah Municipality and SCTA. Therefore, the newly-established municipality was the local authority that directly worked on the built conservation policy designed by the national bodies and consulted by the international experts [13].

\subsubsection{Designating tourist corridors}

The UNESCO Policy emphasises the importance of tourism development by stating: "This policy is based on tourism development" [11]. Therefore, the policy focuses on the main axes that were selected as priority paths for the tourist corridors "attractions" revitalization. Tourism development in Historic Jeddah is reflected by the upgrading and rehabilitation of main corridors (see Fig. 1) that cross the dense fabric of the new nominated property (NP) in light of ICOMOS recommendations. These privileged paths that were studied in detail by Jeddah Municipality in 2010 would favour access to NP for visitors and offer a privileged and preserved urban environment to locals, Saudis and non-Saudi tourists alike [14]. This was a radical shift in the previous built heritage conservation policies that Historic Jeddah witnessed during the last five decades in terms of focusing on the touristic approach to conserve the heritage area. These corridors have a great impact on the entire built heritage conservation efforts by all stakeholders, because a large part of it is located on NP and it pervasive within the heritage area.

\subsubsection{New traffic circulation rules}

Most of the physical interventions in Historic Jeddah have followed the touristic approach (tourist corridors with a variety of focal points and architectural monuments). This section describes the new automobile and pedestrian network and car parking system in Historic Jeddah, which have brought about some physical transformations in the area and, the author believes this will definitely have a huge physical impact on Historic Jeddah in the near future. The author argues that the circulation network system, suggested by the RMJM in 1979 and implemented by the Jeddah Municipality from 1980-2006, has had negative impacts on the urban fabric of the old heritage district by disconnecting the historic buildings from each other. However, in 2011, Historic Jeddah Municipality, under SCTA office supervision, designed new road access in order to cope with the tourist corridors that were already designated in 2010-2011 [13].

The head of the Historic Jeddah Municipality stated: "The new circulation network is based on the tourism plan designed for Historic Jeddah by different actors" [15]. He added that, a meeting with the SCTA officers and Jeddah Traffic Agency officers took place in 
Historic Jeddah to find a practical and feasible solution to preventing vehicles from entering NP. As a result of this meeting, a new traffic rule has been introduced to regulate the number vehicles that can enter NP initially, which will later apply to the whole historical area [16]. This approach, as the head of the SCTA office in Historic Jeddah mentioned [13], is based on blocking the main entrances to NP from the three main sides: the west side in Aldahab Street close to Qabil Street, the Anaba axis in the north (which most visitors use to enter Historic Jeddah) and, finally, the Alalawi Souk on the eastern side, which are the main old entrances to NP.

Fig. 1 illustrates how the local authorities have blocked the existed access to NP in order to protect it from overcrowding and the destruction that vehicles can cause. The justification for blocking these streets' access from three main axes (north, west and east) was to make NP "no automobile zone" and ready for any conservation efforts without any distractions and restrictions [16]. The general supervisor of the National Built Heritage Centre commented:

"Historic Jeddah becomes a heritage area designed to accommodate pedestrians, both

tourists and visitors, especially after the significant number of visitors during the

Saudi national day celebration and Kona Keda Festival. It seems that now Historic

Jeddah is in the right conservation track" [17].

However, the local authorities' solution, on one hand, has prevented vehicles from entering NP, which reduces the inconvenience and noise not to mention the environmental pollution and harm to the homogeneity of the heritage in the area. On the other hand, it has caused parking problems in different areas of Historic Jeddah, such as Aldahab Street. The "no automobile zone" rule led to the accumulation of cars belonging to the residents, shopkeepers, visitors and others. Thus, by the end of 2013, a "pay and display meter" car parking system has been introduced in Historic Jeddah in order to reduce the number of vehicles, with designated car parks outside the heritage area, which is part of the protection and management scheme. This solution was first used in Historic Jeddah and the entire city.

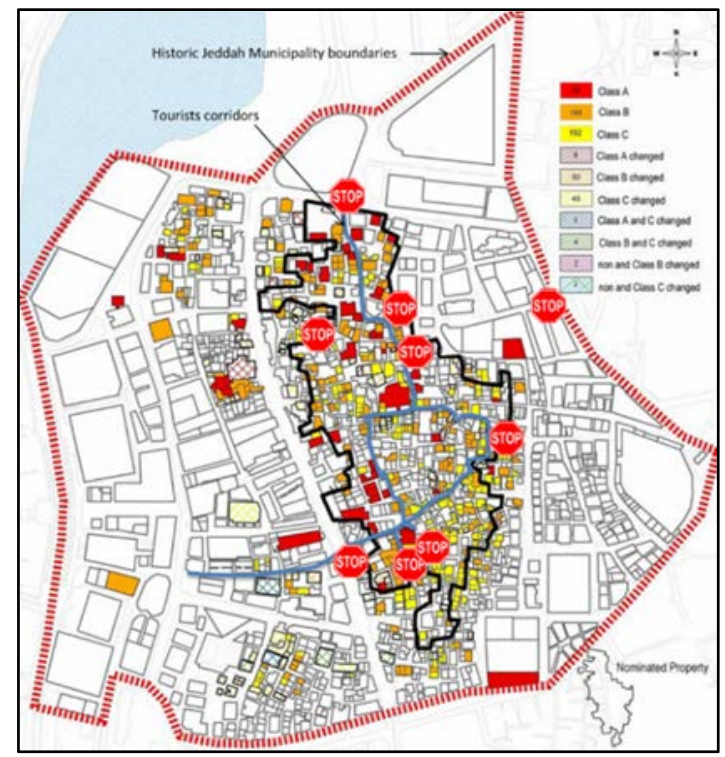

Figure 1: The tourist corridors and the new circulation rules (blocking) from Kona Keda Festival in 2013 [16]. (Source: adapted by the author.) 
A house-owner who is also a shopkeeper [17], who lives outside the historical district, argued that designating a large part of Historic Jeddah (NP) as an automobile-free zone was a vital decision, which Historic Jeddah has needed for a long time. He thinks, however, that this approach was poorly planned and will cause more problems in the near future in terms of accessing the shops and markets, which are considered the backbone industry of the historic area. In June 2014, Okaz report [14] shows that the municipality has designated several drop-offs and loading areas at the edges of NP. This means that the decision-makers in Historic Jeddah have incorporated the views of the house-owners, shopkeepers and all other stakeholders when revising the plans for Historic Jeddah. The author claims that the other key actors' voices have, for the first time in Historic Jeddah, been heard and translated into concrete measures, and this is an example of the concerned stakeholders' involvement in the conservation process, which might by via the house-owner representative committee or any other channel.

\subsubsection{Improving the public spaces}

The local authority of Historic Jeddah was in charge of upgrading the historic district in order to cope with the new vision (UNESCO); therefore, the Historic Jeddah Municipality made notable efforts at both the urban and architecture levels. Historic Jeddah Municipality had undertaken several tasks at the public urban spaces level in Historic Jeddah, which may be seen as re-paving the main axes in the historic area and rearranging the souk, which are both located on the selected tourist corridors.

\subsubsection{Designating Historic Jeddah a venue for different local and national occasions}

A high number of local and national occasions have taken place in Historic Jeddah before and after NP was inscribed on the UNESCO WHS list with significant impacts on the physical condition. However, the author visited Historic Jeddah several times during fieldwork trip (June-November 2013) and again visited the case study in August 2014, two months after UNESCO's inscription on 23 June 2014. Many changes had occurred in the historical area, especially in the tourist "attraction corridors". Extensive restoration had been undertaken on the facades of the historic buildings located in the corridors, and new facilities had also been added to suit the historical context of the area, such as new pavements, lighting columns and so on. The author felt that dramatic changes had occurred in the core of the area. "The average visitor to the inscribed area of Historic Jeddah can feel the integration of a different urban pattern", one visitor commented. The public transportation system (mini cars "golf cars" and minibuses) for the disabled and VIPs were provided for visitors during busy events, such as Saudi National Day and Kona Keda Festival. Tourist information desks were located at the main gates to the inscribed historic area, and several tourist tours were provided under the supervision of the SCTA.

\subsection{The policy impacts on Historic Jeddah architectural typology (historic buildings)}

There were no major changes that occurred during the previous policy (i.e. SCTA Policy 2006-2010) because of the short policy implementation period and lack of legal coverage. However, during the first five years of the UNESCO Policy, there were also no notable changes in the heritage typology as traditional "heritage" compared with the 2009 map that $\mathrm{RC}$ Heritage (the international consultant assigned by SCTA) produced as part of the first nomination file. Most of the built environment components (traditional houses, narrow streets, small squares, souk systems and other) remained as they had been at the last survey, conducted in 2009. This meant that the local authorities had preserved the traditional urban 
fabric of Historic Jeddah for buildings' integration and interdependence. Despite the lack of changes to the urban fabric, here, the author will focus on the changes to the traditional buildings "heritage" typology that occurred during the first five years of the UNESCO Policy's implementation. Most of the typological surveys that took place in Historic Jeddah during the UNESCO Policy (Jeddah Municipality 2011, SCTA 2013 and the author's surveys) concentrated on the classified traditional buildings in order to understand the physical changes that have occurred. This section focuses on the impacts of the UNESCO Policy on the architectural topology of Historic Jeddah. This will be explained by analyzing the historical buildings' classes, the impacts of attempting, then inscribing, the area to the UNESCO WHS list and finally studying a number of historical buildings that have been conserved in Historic Jeddah (see Fig. 2).

During Jeddah Municipality surveys in 1986 there were more than 900 heritage buildings in Historic Jeddah, although the recent surveys (2011, 2013 and 2014) show only 553 reminded. This means that, since Mathew's Policy of the 1970's, Historic Jeddah has lost around 350 heritage buildings. The head of Historic Jeddah Municipality mentioned that most of these historic buildings had collapsed or been burned down or destroyed, either accidently or on purpose [15]. The author argues that the poor implementation of Mathew's Policy (in terms of protection, management and development) by Jeddah Municipality has led to the loss of such a huge number of historic buildings in Historic Jeddah since the 1970s. Fig. 2 illustrates the physical changes made to the heritage buildings that were classified by the RMJM in the 1970s. Fig. 2 and Table 1 present that the vast majority (493 buildings: 98\%) of the historic buildings are located in the historical district designated by Mathew's Policy; they are also located in the recent NP. All heritage buildings' classes have undergone some physical changes. The traditional buildings from Class $\mathrm{B}$ and $\mathrm{C}$ were the least altered class of buildings, and most of them are located in NP. The majority of Class A buildings were also located in NP (40 buildings: 76\%). Therefore, the author argues that the concerned

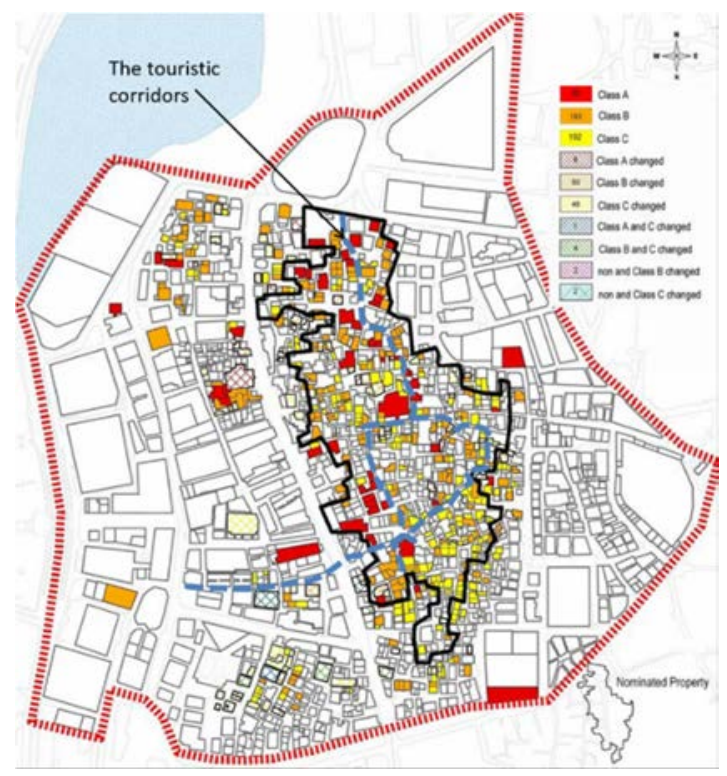

Figure 2: The changes in the heritage buildings' classification in 2014, overlapping the previous surveys plus the touristic corridors. 
Table 1: $\quad$ Changes in the traditional buildings classification in Historic Jeddah by 2014. (Source: author.)

\begin{tabular}{|c|c|c|c|c|c|c|c|c|}
\hline \multirow[b]{2}{*}{ Class } & \multirow[b]{2}{*}{ Number } & \multirow[b]{2}{*}{ Changed } & \multicolumn{4}{|c|}{ Changed from one class to another } & \multirow{2}{*}{$\begin{array}{l}\text { Number } \\
\text { located in } \\
\text { the NP }\end{array}$} & \multirow{2}{*}{$\begin{array}{l}\text { Number located } \\
\text { outside the NP }\end{array}$} \\
\hline & & & $\mathrm{A}-\mathrm{C}$ & $\mathrm{B}-\mathrm{C}$ & Non-B & Non-C & & \\
\hline A & 52 & 8 & 1 & - & - & - & 40 & 12 \\
\hline $\mathrm{B}$ & 193 & 50 & - & 4 & 2 & - & 113 & 80 \\
\hline $\mathrm{C}$ & 192 & 49 & - & - & - & 2 & 127 & 65 \\
\hline Total & 437 & 107 & 1 & 4 & 2 & 2 & 280 & 157 \\
\hline$\%$ & 100 & 19 & 12 & 8 & 8 & 4 & 64 & 36 \\
\hline
\end{tabular}

authorities have used these surveys when choosing the boundaries of NP that was inscribed on the UNESCO WHS list in 2014. To confirm this argument, there were only eight heritage buildings in NP that have changed to a lower classification. It seems that NP was carefully chosen in order to present the Jeddawi urban and architectural beauty without distractions.

\subsubsection{The impacts of attempting to inscribe and (then) inscribing NP on} the UNESCO list on the conservation process in Historic Jeddah

The UNESCO Policy, as previously reported, was based on the UNESCO (ICOMOS committee) recommendations to inscribe the historical districts and beyond, which basically relies on the relationship between heritage sites, tourism development and stakeholders' involvement. To understand this impact on the actual conservation process in Historic Jeddah, the author has analyzed some of the conservation (revitalization) projects that have been implemented in the area since the beginning of the policy in 2010. This has been studied by analyzing the three physical surveys that have taken place in Historic Jeddah since 2010. The actual impact of the UNESCO Policy on the heritage sites in Historic Jeddah can be divided into three main phases: before choosing the NP (Jeddah Municipality survey in 2011), after designating the NP (SCTA survey 2013 and part of the author's survey during his fieldwork in 2013) and finally after inscribing Historic Jeddah on the UNESCO list (the author's visits to the case study in 2014-2015).

Firstly, the Jeddah Municipality survey in 2011 shows that 119 heritage buildings were being revitalized, the majority of which were under construction. Some of the revitalization projects had already begun before 2011, but most of them were launched at the beginning of the policy in 2010. All stakeholders had the chance to be involved and participate in these conservation projects (governmental, public and private sectors), but mainly the governmental bodies at this stage. Furthermore, the entire historical area was the target of revitalization projects.

Secondly were the SCTA and the author's surveys in 2013. New conservation projects were found both inside and outside the nomination area selected. It was noticeable that most of the conservation was taking place inside NP due to the expected ICOMOS committee meeting in summer 2013. Last but not least, there were the author's visits to the case study area after UNESCO's inscription in July-August 2014 and January 2015. Basically, the concern was with the inscribed property (previously NP), especially around the tourist corridors, with a small number of projects taking place outside the inscribed property. Finally, Historic Jeddah has become more like a workshop due to the large number of projects being implemented and still under construction, mostly inside the inscribed area.

This also indicates the conservation status in 2011 and how it was comprehensive (entire area), but how it had become more selective by 2013-2015 (NP and tourist corridors). Additionally, the first survey that was conducted in 2011 shows that most of the actors were 
from the governmental bodies (Jeddah Municipality and SCTA), then, this situation had changed, as the SCTA and author surveys (2013, 2014 and 2015) indicated. The individual heritage activates and NGOs have been noticeably involved in physical projects, such as AlSaloum House and Badeeb House. The interesting thing was that most of these projects have used the touristic approach by revitalizing the heritage building into new functions and uses. Just a few revitalization projects were finished and have been opened to the public, but most of these projects are in their final stages.

\subsubsection{Conservation projects}

The author argues that, during the initial five years of the UNESCO Policy, more conservation projects have been implemented in Historic Jeddah than in the conservation projects in Mathew's and SCTA's policies periods together (1970-2010). This can be seen in the quantity and the quality of the conservation initiatives and the variety of stakeholders at both the physical and the intellectual levels. The UNESCO Policy has been dependent on involving all stakeholders in conserving Historic Jeddah physically to ensure that the conservation efforts would be sustainable and continuous. Thus, several selective heritage sites, mainly buildings were chosen for analysis in order to understand the actual impacts of the UNESCO Policy on the ground. The criteria for choosing these heritage buildings were:

- The conservation initiatives must be implemented by different stakeholders;

- They must have started the revitalization process during the UNESCO Policy period;

- The heritage sites must be located in Historic Jeddah (inside or outside the nominated/inscribed property);

- Finally, they must have different building uses, ownership types and significance classes.

Fig. 3 presents the selected heritage sites. Most of the chosen heritage sites were located in NP (that became the inscribed property) and lie within the tourist corridors, because of the focus of the governmental bodies on inscribing Historic Jeddah. Three main stakeholder categories have implemented conservation projects in Historic Jeddah during the UNESCO Policy: the governmental bodies, individual(s), local heritage activists and advocates (includes house-owners, heritage conservation activists and advocates) and NGOs.

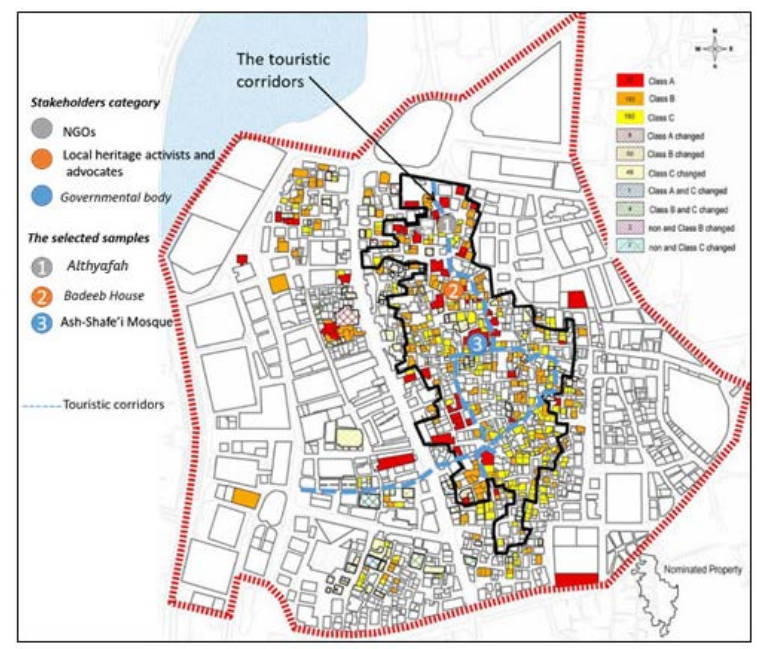

Figure 3: The selected heritage sites chosen by the author in 2015. 
Fig. 3 also presents the variety of stakeholders that participated in actualizing the UNESCO Policy in Historic Jeddah via restoring, conserving or rehabilitating heritage buildings. The same figure, also, shows that there were different architecture topologies in terms of the heritage buildings: usages, heights, locations and so on. Here three heritage buildings will be studied and analyzed, which as follows:

Althyafah Coffee and Tea Museum

A heritage building was part of Anabah Mosque, Class B, in Alsham Quarter has restored and rehabilitated by Jeddah Architectural Preservation Society (JAPS). The head of the SCTA office in Historic Jeddah (2013) commented:

"By the end of the 1970's, it was neglected and abandoned until JAPS rented it from the Ministry of Islamic Affairs, Da 'wah, Guidance, and Endowments in 2013. This is an example of the new shift in dealing with the public organization as a vital partner in the revitalization process of Historic Jeddah" [18].

As the JAPS website stated, the idea behind restoring and rehabilitating part of Anabah Mosque was to establish a traditional museum about the coffee and tea customs in Historic Jeddah. They named it the Althyafah [hospitality] Museum of Coffee and Tea. A local architectural firm (recognized by the SCTA) designed the new museum, bearing in mind the traditional materials and forms [19]. Wooden beams, plaster and limestone were the main materials used, which are traditional, and the architectural form was restored, with traditional decorative features on top of the building. During the SCTA and the author's surveys, the building of the museum had commenced, and recently (June 2015) the restoration is almost complete, so it might be open to the public very soon. Fig. 4 shows how fast the restoration process has taken place. The author believes that, even though the heritage site is small, it marked a huge shift in the conservation discourse in the area by allowing for it new uses that show the traditional way of life of the area rather than recreating something that already existed. A public organization such as JAPS caused a significant shift in public participation in the built heritage conservation projects in Saudi. This is an example of the UNESCO Policy supporting the NGOs by giving them the chance to participate "physically" by rehabilitating said heritage site and "intellectually" by reviving the Hejazi traditions via the public museum.

Badeeb House

The UNESCO Policy has made a revolutionary notion in terms of involving such a variety of stakeholders in the conservation process that led to the creation of many interesting conservation projects. Badeeb House rehabilitation project was one of them. Badeeb House is a Class B heritage building. In 2011, Mr. Ahmed Badeeb bought the Salamah House (Badeeb's uncle) in order to revitalize it [23]. In August 2013, the author interviewed Badeeb

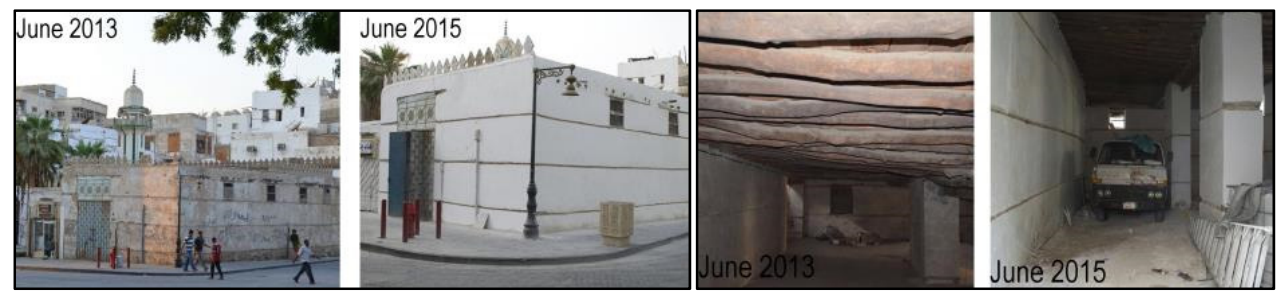

Figure 4: Althyafah Coffee and Tea Museum between 2013 and 2015 [18]. (Source: author.) 
as a heritage advocate before recognizing his initiatives as a house-owner. However, Badeeb said:

"I spent two years (2011-2013) revitalizing the Salamah family house at a cost of around 1 Million Saudi Riyals $(£ 170,000)$. I had some difficulty obtaining the right permissions from Jeddah Municipality with the SCTA's support, legally and technically. The purpose in revitalizing this traditional house is to create a traditional museum that serves the heritage area" [20].

Badeeb's initiative complied with the UNESCO Policy objectives in terms of attracting visitors and tourists to Historic Jeddah by reusing a traditional house for a new purpose, which is a museum in this case. The museum initiative might be a repeated idea, but Historic Jeddah deserves such projects in order to be conserved. This initiative was considered one of the initial house-owners' projects in Historic Jeddah. He is not an expert in built heritage conservation but has a sense of the historical value of the traditional Hejazi house. Regardless of the positive initiative at the construction level in terms of the materials and colours used (Fig. 5), the author argues that several mistakes were made during the revitalization process. Initially, Badeeb used a modern ventilation system (air-conditioning units) (Fig. 5) rather than a traditional "natural" ventilation system or central air-cooling system like that used in Angawi house, Almakkayah. Another mistake was that the bathroom fittings were too modern in that it does not suit a traditional Hejazi house. It seems that there was a lack of supervision by the SCTA and Jeddah Municipality, which led to these mistakes. Although, the author claims that Badeeb's revitalization project can be described as successful due to the scarcity of such projects.

Ash-Shafe'i Mosque

The SCTA is a national organization interested in conserving and promoting Saudi heritage sites for tourism purposes. As result, most of the SCTA's "physical" conservation efforts in Historic Jeddah were concentrated on the most significant monuments that have considerable value for Islamic and Hejazi architecture. The SCTA has focused on restoring and rehabilitating several main masjids [mosques] in NP due to its architectural, social and religious values. There are many mosques in Historic Jeddah that reflect the authenticity of the Islamic/Hejazi architectural style. It is essential to mention that all of the mosques in Saudi Arabia are owned or supervised by the Ministry of Islamic Affairs, Da'wah, Guidance, and Endowments; thus, the SCTA Policy has implemented a partnership agreement with the ministry. This confirms my argument that the SCTA Policy paved the way for further efforts
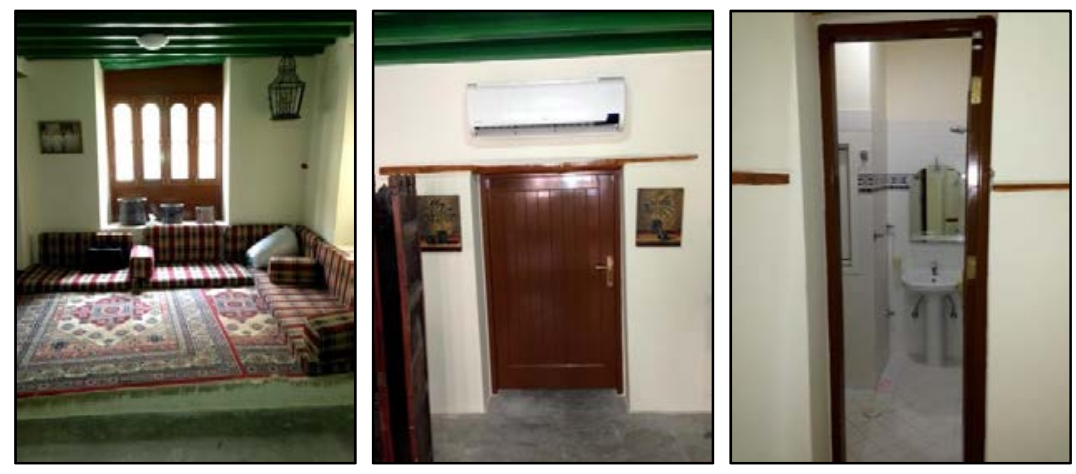

Figure 5: Badeeb House. (Source: author, 2013.) 
to implement the UNESCO Policy easily and smoothly (legally). There is no better example than the Ash-Shafe'i Mosque restoration and rehabilitation project to mention in this context. Ash-Shafe'i Mosque is classified as a Class A heritage building. The restoration of Masjid Ash-Shafe $i$ has been entrusted to the Turath Foundation, the technical arm of the SCTA, and the Centre for Conservation and Preservation of Islamic Architectural Heritage took charge of the restoration, conservation and rehabilitation work. Following a thorough survey of the building, work began in 2011 and was completed in June 2015 [15].

The conservation project, costing a total of about 10 million Riyals (around $£ 2$ million), has remarkably permitted the uncovering of a vast underground cistern below the courtyard and the obtaining of a precise understanding of the historic evolution of the building located at the very heart of NP. Conducted according to international standards for conservation, the restoration of Ash-Shafe'i mosque was the first comprehensive conservation project to be carried out in Jeddah. The mosque was closed from 2011 to June 2015. The Jeddah Municipality reports (2006 and 2010) show that Ash-Shafe'i Mosque was named several times to be repaired, especially with its poor construction, stone walls and ceiling [21]. None of these repairs materialized, but the UNESCO Policy, with SCTA support, accelerated the process of restoring and reviving the old traditional mosque [8]. Fig. 6 shows the results of the restoration of Ash-Shafe'i Mosque. The author argues that the most effective aspect of the UNESCO Policy is that it puts pressure on the concerned authorities and stakeholders to speed up the restoration, rehabilitation and revitalization projects in Historic Jeddah. Finally, such projects will attract more visitors and tourists to Historic Jeddah, whether in the inscribed area or the buffer zone.

\section{CONCLUSION}

Historic Jeddah has witnessed three main built heritage conservation policies since the 1970's, namely Mathew's Policy 1970-2006, SCTA Policy 2006-2010 and UNESOC 20102020. All these policies had impacts on the built heritage place, however this paper focused on the current policy "UNESCO Policy 2010-2020". The idea of that policy was based upon the legal, the logistic and the financial support to enable Historic Jeddah to be revived with prearranged vision that has a touristic nature.

However, most of the above conservation efforts (policies) shared a similar endeavor, which was to adhere to the SCTA vision and meet the UNESCO standards. Moreover, most

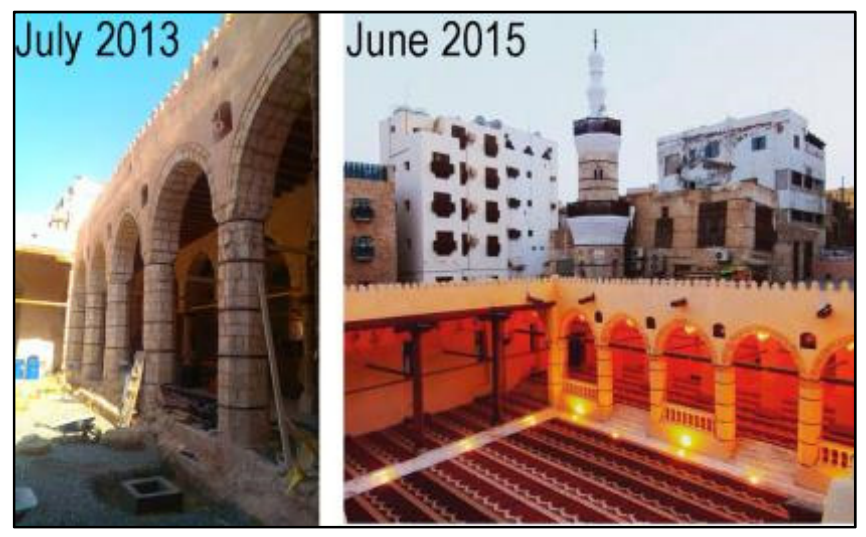

Figure 6: The restoration of Ash-Shafe'i Mosque courtyard between 2013 (Source: author) and 2015 (Source: WAS). 
of the above priorities have a similar framework with a supreme objective, which is to make Historic Jeddah a tourist destination with cultural, urban, architectural and economic sustainability. Designating the nominated property "NP" (later the inscribed property) has accelerated conservation in Historic Jeddah. Many revitalization projects, undertaken by a variety of stakeholders, have been launched since the implementation of the UNESCO Policy, which is one of the UNESCO Policy objectives (involving all concerned stakeholders).

Some examples presented the co-operation between the house-owners, NGOs and the concerned governmental bodies. For instance, Badeeb House and Althyafah Coffee and Tea Museum have been revitalized in order to adhere to the UNESCO Policy that focuses on using the historical values of the place to promote tourism or at least supported the idea legally and technically. However, Badeeb House was restored and planned to be used as a museum without any governmental supervision, which led to the finding of a couple of mistakes. Regardless of the mistakes that occurred in certain conservation projects, the author claims that the UNESCO Policy has changed the course of built heritage conservation in Historic Jeddah in the light of the projects that were implemented and planned.

Finally, the large number and the variety of conservation projects that have been implementing in Historic Jeddah since regulating the UNESCO Policy in 2010 (more than 40 projects) indicates effectiveness of the policy. This means the policy is putting Historic Jeddah in the right track, it is early to judge the level of the success but until the present the policy is making a great progress compering with the previous two policies due to the change in the entire discourse, attitude and vision, which is promoting tourism via built heritage sites.

\section{REFERENCES}

[1] Macdonald, S. \& Cheong, C., The Role of Public-Private Partnerships and the Third Sector in Conserving Heritage Buildings, Sites, and Historic Urban Areas, Getty Conservation Institute: Los Angeles, 2014.

[2] Soilman, M., Sustainable development between piecemeal and urban based conservation: case study of Jeddah. International Journal of Academic research, 2(5), 2010.

[3] Rahman, S., Heritage Tourism and the Built Environment (Unpublished $\mathrm{PhD}$ thesis). University of Birmingham - School of Geography, Earth and Environmental Sciences, 2012.

[4] Bokhari, A., Conservation in the Historic District of Jeddah. Proceedings of the International Conference on Redeveloping and Rehabilitating Traditional Areas, King Saud University, Riyadh, KSA, 2006.

[5] Harrison, D. \& Hitchcock, M. eds, The Politics of World Heritage: Negotiating Tourism and Conservation, Channel View Publications: Cleveden, 2005.

[6] Radoine, H., Conservation based cultural, environmental, and economic development: the case of the walled city of Fez. The Human Sustainable City: Challenges and Perspectives from the Habitat Agenda, ed. L. Fusco Girard, Ashgate: Burlington, 2003.

[7] Bagader, M., The evolution of built-heritage conservation concept in Saudi Arabia since the 1970s until 2014. Research and Heritage: Research papers on Architectural Heritage for the Fourth National Built Heritage Forum, 1-4 December, Saudi Arabia, pp. 22-37, 2014

[8] Bagader, M., The Evolution of Built Heritage Conservation Policies in Saudi Arabia between 1970 and 2015: The Case of Historic Jeddah (Unpublished PhD thesis), University of Manchester, UK, 2016. 
[9] Fadan, S., Personal communication, August 2013, Head of SCTA Office in HJ, Jeddah, KSA.

[10] SCTA, The SCTA initiatives towards conserving the Saudi heritage. The SCTA Annual Report, Riyadh, 2010 [in Arabic].

[11] Historic Jeddah Nomination, Historic Jeddah: the Gate to Makkah. Submitted to the UNESCO by SCTA in 2013, Saudi Arabia - Riyadh, 2013.

[12] SCTA, Historic Jeddah: conservation efforts. The SCTA Annual Report, Riyadh, 2012 [in Arabic].

[13] Historic Jeddah Municipality, Annual report about Historic Jeddad, Jeddah - KSA, 2013.

[14] Okaz, Historic Jeddah after the SCTA. A special report about Historic Jeddah, Saudi Arabia - Jeddah, pp. 13-25, 2013 [in Arabic].

[15] The head of the Historic Jeddah Municipality, Personal communication, July 2013, Jeddah - KSA.

[16] Historic Jeddah Municipality, Annual Report, Jeddah - KSA, 2011 [in Arabic].

[17] Al-Naim, M., Personal communication, June 2013, Head of NBHF, Riyadh - KSA.

[18] Al-Amoudi, M., Personal communication, June 2013, Jeddah - KSA, house-owner.

[19] JAPS, Online. https://plus.google.com/101721907882611920686/posts. Accessed on: Jun. 2015.

[20] Okaz, A., The NGOs efforts in Historic Jeddah after the SCTA, A special report about Historic Jeddah, Saudi Arabia - Jeddah, pp. 22-28, 2014 [in Arabic].

[21] Badeeb, A., Personal communication, August 2013, the owner of Badeeb House in HJ, Jeddah - KSA.

[22] RC Heritage, Online. www.rcheritage.com. Accessed on: Apr. 2015. 